\title{
Inclusión financiera en el ámbito rural mediante cajas de ahorro. Estudio de una experiencia en México
}

\author{
Federico Martínez-Carrasco Pleite,* Ana M. Muñoz Soriano, ${ }^{* *}$ \\ Maged Eid,** José Colino Sueiras***
}

Perfiles Latinoamericanos, $24(48)$

2016 | pp. $185-211$

DOI: $10.18504 / \mathrm{pl} 2448-008-2016$

\begin{abstract}
Resumen
Los niveles de pobreza de un importante porcentaje de la población de muchos países en desarrollo se acompañan, con frecuencia, de la falta de acceso a productos de ahorro, pago, crédito o seguro, lo que determina una exclusión financiera. Aquí se presenta el proyecto de cajas de ahorro auspiciado por la Fundación León XIII en México. Tras describirse esta experiencia informal de fomento del ahorro, se presentan los datos de una encuesta realizada entre 218 beneficiarios del proyecto. Su análisis bivariante y multivariante, además de cuantificar las condiciones de vida de sus beneficiarios, proporciona valiosa información acerca de la capacidad de ahorro que la población logra a través de esta iniciativa, segmentando a sus beneficiarios por sus características y esfuerzo ahorrador.
\end{abstract}

\begin{abstract}
Poverty levels that lives a significant percentage of population in many developing countries, often accompanied by a lack of access to savings products, payment, credit or insurance, which determine high levels of financial exclusion. In this paper, we present the case of a savings bank project developed a decade ago by the León XIII Foundation in Mexico. After analyzing this experience, we present the data obtained with a survey realized to 218 beneficiaries. The bivariate and multivariate analysis of this information, besides allowing quantifying the living conditions of the beneficiaries, provides valuable information about the saving capacity of the population reached through this initiative, segmenting its beneficiaries in consideration of their characteristics and their saving effort.
\end{abstract}

Palabras clave: exclusión financiera, cajas de ahorro, pobreza, México, Fundación León XIII. Keywords: Financial exclusion, savings bank, poverty, Mexico, León XIII Foundation.

* Profesor Titular de Universidad, Dpto. de Economía Aplicada, Universidad de Murcia, España.

** Máster Universitario. Desarrollo Económico y Cooperación Internacional, Universidad de Murcia, Espańa.

*** Catedrático de Universidad, Dpto. de Economía Aplicada. Universidad de Murcia, España. 


\section{Introducción}

Exclusión financiera, pobreza y vulnerabilidad

$\square$

l término exclusión financiera surgió por primera vez en 1993, de manos de geógrafos preocupados por el acceso físico limitado a los servicios bancarios por el cierre de sucursales bancarias en Estados Unidos y Gran Bretaña (Leyshon \& Thrift, 1995). Una definición actualizada del término la aporta la Comisión Europea (2008, p. 10) cuando señala que "la exclusión financiera se refiere a un proceso mediante el cual las personas se encuentran con dificultades en el acceso y/o uso de los servicios y productos financieros en el mercado general que sean apropiadas a sus necesidades y que les permita llevar una vida social normal en la sociedad en la que pertenecen". Esta definición implica, tal y como recuerdan Zubeldia et al. (2008: p. 210), que la exclusión financiera "es una causa y también resultado de la exclusión social". El reconocimiento de gobiernos, donantes e instituciones financieras internacionales sobre la importancia del acceso a servicios financieros en la mitigación de la pobreza y la disminución de la vulnerabilidad de los más pobres, llevó a la creación, en 2012, de la Red Global de Políticas Financieras de Bancos Centrales de Países en Desarrollo y Emergentes, denominada Alianza para la Inclusión Financiera, con el compromiso de luchar por la inclusión financiera (Allan et al., 2013). Ese documento recordaba las múltiples barreras que enfrenta la inclusión de los más pobres del mundo, destacando como principales limitaciones:

a) la falta de comprensión financiera o información entre proveedores de los servicios y los usuarios;

b) la discriminación por género y por edad existente, que determina una mayor exclusión de mujeres y jóvenes;

c) los bajos ingresos de la gente pobre y lo errático de sus flujos de efectivo;

d) la falta de productos adecuados y los procesos de los proveedores formales de servicios financieros, que no se adaptan a las necesidades de los más pobres;

e) la existencia de distancias geográficas y costes de transacción para las entidades que operan en lugares remotos, así como los costes de transporte y de oportunidad para que las personas accedan a las instituciones financieras formales;

f) las políticas nacionales e internacionales, que impiden la inclusión financiera de las personas más pobres del mundo.

Esa misma fuente señalaba la importancia de la inclusión financiera en el nuevo marco diseñado por la onu en la consecución de los Objetivos de Desa- 
rrollo del Milenio, para el que resulta necesario más controles y relaciones más equilibradas que protejan a las personas más pobres y vulnerables, por lo que se debe ampliar el acceso de la población a una educación financiera, construir más puentes entre los sectores formales e informales, y reconocer la importancia del ahorro y sus grupos de inclusión financiera informales, como paso previo a una sensata transición a la inclusión financiera formal.

Desde 2012, el Banco Mundial, en colaboración con la Fundación Bill y Melinda Gates, proporciona información detallada sobre la inclusión financiera en el mundo a través del Global Findex (Demirguc-Kunt $\&$ Klapper, 2012). Esos datos permiten comprobar cómo en la actualidad el $50 \%$ de las personas de más de quince años no dispone de una cuenta en una institución financiera formal, y que son muy significativas las diferencias entre regiones, economías y características de las personas en términos de acceso a servicios financieros, lo que determina la manera en que los ciudadanos ahorran, se endeudan, realizan sus pagos o gestionan sus riesgos. Esta base de microdatos muestra la importancia del problema de la exclusión financiera a nivel mundial con cifras como que, cerca de un $77 \%$ de los pobres en el mundo (personas con ingresos inferiores a dos dólares al día) no tienen una cuenta bancaria, cuando a nivel mundial ese porcentaje es del 50\%; o que 55\% de los prestatarios en los países en desarrollo deben recurrir a medios informales para conseguir un préstamo, ahorrar o protegerse ante riesgos, lo que hace de la exclusión financiera un reto para el desarrollo humano.

El problema de la exclusión financiera afecta de manera desigual a los países, de tal modo que, mientras en los de ingresos altos cerca del $90 \%$ de su población accede a una cuenta financiera en una entidad financiera formal, en países de ingresos medianos el porcentaje se reduce significativamente. Como en el caso de México —objeto de análisis en este trabajo_-, donde, según datos del Banco Mundial (2012), solo el 27\% de las personas adultas están "bancarizadas", con importantes brechas entre hombres (33\%) y mujeres (22\%), y entre población urbana (37\%) y rural (11\%). La utilización de entidades financieras formales como medio de pago es también muy reducida en México, con menos del 5\% de su población adulta con una cuenta en la que reciba remesas del extranjero - pese a la importancia del proceso migratorio en este país—, o en la cual reciba pagos del gobierno o sus propios salarios. La inclusión financiera como utilización de servicios de ahorro formales también es muy reducida: apenas un $7 \%$ dispone de una cuenta de ahorro en una entidad financiera, mientras que $5 \%$ prefiere depositar sus ahorros fuera del hogar, a través de clubes u otros sistemas informales como "tandas" o "rondas" (Clavellina, 2012). De igual modo, el porcentaje de población que indicó haber recibido un crédito en alguna institución financiera en el último año era del 8\%, cifra próxima a lo alcanzado en otros países latinoamericanos. 
Según datos de la Comisión Nacional Bancaria y de Valores (CNBv), el sistema financiero formal en México se integra, por un lado, por el sector bancario, conformado por bancos comerciales múltiples o comerciales, y por bancos de desarrollo (Bansefi o Banjército), uniones de crédito, sociedades financieras de objeto limitado (Sofol), sociedades financieras de objeto múltiple (Sofomes) y corresponsales bancarios con contrato con una entidad bancaria; y, por el otro, por las entidades de ahorro y de crédito popular, como cooperativas y sociedades financieras populares (Sofipos) que, de acuerdo a la forma legal adoptada, se integrarían en las catalogadas como instituciones microfinancieras (Esquivel, 2008: p. 167), supervisadas por la Secretaría de Economía, tras las que se encuentran numerosas organizaciones no gubernamentales (ONG) y asociaciones civiles. En este último grupo predominan las iniciativas de las comunidades — que dirigen su actividad a la prestación de servicios a la población con menos ingresos y al sector informal—, y son múltiples las formas organizacionales que adoptan (ONG, cooperativas, instituciones no bancarias o bancos comerciales). Si bien la mayor parte del ahorro y crédito del mercado es acaparado por los bancos comerciales, las instituciones microfinancieras ocupan un destacado papel en términos de inclusión financiera (CIF, 2009), pues proporcionan servicios financieros a individuos en situación de extrema pobreza desatendidos y desplazados de los servicios públicos y privados del sector financiero formal. ${ }^{1}$ La dimensión y crecimiento de estas y otras iniciativas resulta difícil de conocer, debido a que son numerosas las formas organizacionales que adoptan (ONG, cooperativas, instituciones no bancarias...), pudiéndose incluir en el sector popular entidades que, si bien prestan servicios al sector informal, algunas "se abstraen a la regulación e incluso a la autorregulación" (Esquivel, 2008: p. 171), causa que hace "difícil llevar un control del desempeño de las microfinanzas en México o dirigir sus políticas a este sector" (CIF, 2009: p. 19).

Según la Encuesta Nacional de Inclusión Financiera (ENIF), realizada por el Instituto Nacional de Estadística, Geografía e Informática (INEGI, 2012; 2013), si bien el 95.5\% de la población total en México dispone de al menos un punto de acceso al sector financiero, solo $35.5 \%$ de su población adulta contaba en 2012 con una cuenta de ahorro en una institución formal; en orden de importancia: cuentas de nóminas, de ahorro, de cheques o depósitos a plazo; y solo $27.5 \%$ disponía de algún producto de crédito, como tarjetas departa-

1 Para una revisión de experiencias alternativas de entidades microfinancieras en México —con diferentes metodologías - dirigidas a grupos de individuos pobres o en situación de pobreza extrema desplazados o ajenos a servicios financieros formales, se recomienda la lectura de Conde (2000a; 2000b). 
mentales y bancarias, créditos personales, grupales y de nómina, hipotecarios o automotrices.

Por lo tanto, la población adulta que finalmente utiliza algún servicio financiero formal alcanza apenas el $56 \%$ de la población adulta, ya sea con cuentas de ahorro, de crédito, seguros (22.0\%) o de ahorro para el retiro (27.8\%). Según esa misma fuente (INEGI, 2013), al hecho de que $44 \%$ de la población adulta en México no cuente con ningún producto financiero formal, hay que agregar que el sistema de ahorro más frecuente empleado (43.7\%) se da mediante mecanismos diferentes a los ofrecidos por las instituciones financieras formales, al igual que sucede con productos de crédito (33.7\%). Esos datos evidencian la importancia que en México aún tiene el uso de mecanismos informales de ahorro y crédito, lo cual obedece a numerosas barreras de oferta y demanda.

Esos obstáculos al uso y acceso a servicios financieros se han descrito ampliamente en la literatura (Mendizábal et al., 2008; Vázquez, 2013; Peña et al., 2014), la cual destaca la limitación que ello supondría: el bajo nivel de ingresos de los individuos, su género, su falta de educación y de cultura financiera, su ocupación y la importancia del mercado informal, la exclusión geográfica y el tamańo de la comunidad de residencia, la exclusión que pueden suponer las condiciones de acceso impuestas u otras variables intrínsecas a la cultura o etnia de los individuos que determinan su autoexclusión y preferencia por el uso de mecanismos financieros informales.

Según la Encuesta Nacional de Inclusión Financiera (INEGI, 2012), las principales barreras para la población adulta mexicana que no ahorra serían la falta de ingresos $(73 \%)$, la falta de interés (16\%), no contar con los requisitos necesarios $(5 \%)$, desconfianza en las instituciones (4\%), el cobro de comisiones altas (3\%), la distancia respecto de la sucursal (2\%) y la obtención de bajos rendimientos por sus ahorros (1\%).

Para conocer la desigual cobertura territorial, motivo de la exclusión geográfica existente en el sector financiero formal en México, es preciso acudir al último informe del Consejo Nacional de Inclusión Financiera (CNIF, 2013), realizado con datos de instituciones supervisadas en 2012 por la CNBv. Según esta, solo el $46.9 \%$ de los municipios del país (1152) dispone de sucursales para realizar operaciones, cobertura que se amplía al 59.4\% al contemplar los cajeros automáticos, las terminales de puntos de venta (67.9\%) y los corresponsales bancarios (72.8\%). No obstante, el grado de exclusión lleva a que sea muy alejado el porcentaje de personas que efectivamente acceden a servicios financieros, lo que aumenta la brecha entre los ámbitos rurales y urbanos, de tal modo que la cobertura en los municipios rurales es escasa; y se observa además que las cooperativas y otras formas populares de ahorro son las que tienen en aquellas localidades una mayor presencia e importancia (CIF, 2009). 
En consecuencia, reducir el rezago nacional de México de acceso a servicios básicos que satisfacen las necesidades financieras de cualquier persona (ahorro, crédito, pago y seguros) se torna una necesidad, en especial para los hogares con bajos ingresos, las personas que trabajan en el sector informal y la población del ámbito rural más aislada. Así lo entiende el Centro de Inclusión Financiera (CIF, 2009: p. 5) cuando señala que "la inclusión financiera es una importante meta nacional por un sinnúmero de razones. Tiene el potencial de hacer una valiosa contribución a la economía mexicana y reducir al mismo tiempo la desigualdad social”. La extensión a más personas del acceso a servicios financieros básicos facilitaría las transacciones económicas, posibilitando inversiones e incrementos de productividad; permitiría que los hogares de bajos ingresos administraran mejor sus recursos y oportunidades, con un mayor reconocimiento del valor de su trabajo; mejoraría la calidad de vida de muchos de ellos, al permitirles cubrir necesidades puntuales de educación, salud o vivienda; les proporcionaría una mayor independencia y protección contra la vulnerabilidad a la que están expuestos en términos de fuentes de ingresos y emergencias.

En las últimas décadas, se han hecho numerosos esfuerzos en México — desde instituciones públicas y privadas_ para promover un sistema financiero más incluyente (Heimann \& Gómez, 2009), con reformas del marco normativo - de funcionamiento y supervisión bancaria — y propiciando una más intensa penetración geográfica de intermediarios y puntos de acceso, con la apertura de nuevas sucursales y una importante difusión de tarjetas bancarias (INEGI, 2012). Se ha potenciado la creación de redes de corresponsales bancarios, la inversión en plataformas tecnológicas compartidas y se han implementado programas de subsidios públicos para la ampliación del microcrédito (Morfín, 2009). Se ha posibilitado, además, la utilización de infraestructuras de programas sociales para la difusión de servicios financieros, como la entrega (desde 2012) de los subsidios del Programa Oportunidades, mediante tarjetas prepago o de débito asociadas a una cuenta bancaria (Gutiérrez \& Servan, 2012).

También destaca el efecto de la iniciativa de la "cuenta de nómina" de bajo costo (Vázquez, 2013), o el más reciente desarrollo de nuevos mecanismos de inclusión basados en las tecnologías de la información y la comunicación (TIC), como la banca móvil (Alonso et al., 2013) e Internet (Álvarez et al., 2011). A todas estas medidas habría que unir diversas iniciativas de protección del consumidor y de fomento de la educación financiera, recientemente descritas por Raccanello \& Herrera (2014).

Pese a todos estos elementos y esfuerzos en el ámbito de la bancarización, tal y como se señala en el "Informe oficial del Proyecto de Inclusión Financiera en 2020" del Centro para la Inclusión Financiera en Acción Internacional, es todavía real "la necesidad insatisfecha existente de servicios financieros en Mé- 
xico" (CIF, 2009: p. 34); o como se concluía en un reciente informe del Banco Mundial (Reddy et al., 2013: 13), "a pesar de un fuerte aumento en la disponibilidad de productos y servicios financieros en los últimos años, la inclusión financiera continúa siendo un reto" en México.

\section{El proyecto de cajas de ahorro de la Fundación León XIII}

En este trabajo se analiza el caso del proyecto de cajas de ahorro auspiciado por la Fundación León XIII, organización civil dedicada al desarrollo integral de personas y comunidades en condiciones de pobreza; el cual se configuró como base social para la implementación de otros proyectos productivos y de desarrollo social, con el fin de generar paulatinamente la autonomía y capacidades de los grupos atendidos, bajo la filosofía de que "las mismas personas generan su propio desarrollo” (Fundación León XIII, 2013).

La Fundación León XIII es una institución de asistencia privada (IAP), creada en 1996 por el Instituto Mexicano de Doctrina Social Cristiana (Imdosoc). ${ }^{2} \mathrm{Su}$ objetivo consiste en apoyar a la población mexicana marginada para su integración en la sociedad y brindar asistencia en situaciones de emergencia; inició sus actividades en 1994 en los Altos de Chiapas en coincidencia con el levantamiento armado del Ejército Zapatista de Liberación Nacional (EZLN).

Dicha fundación trabaja en un esquema de intervención que busca romper con el círculo vicioso y dependiente de la pobreza, a fin de mejorar una calidad de vida, en sintonía con otros proyectos existentes en el país relativos a la inclusión financiera con un marcado enfoque de intervención social (Álvarez et al., 2011). Para cumplirlo, el modelo de desarrollo implementado por la Fundación actúa en tres áreas principales: seguridad alimentaria, desarrollo de habilidades y capacidades, y generación de ingresos. Así, contribuye en primera instancia a cubrir las necesidades básicas de las personas y, en un segundo momento, al desarrollo de sus capacidades, lo que reduce las desigualdades sociales y los niveles de pobreza existentes, lo que así crea un tejido social.

El proyecto "Cajas de ahorro" de la Fundación León XIII tiene por meta "fomentar una cultura del ahorro entre los miembros de la comunidad, de tal forma que a través de un modelo de inversión logren generar beneficios para ellos y sus familias", y se opera desde los centros de desarrollo comunitarios de la Fundación en los estados de Chiapas, Oaxaca y Puebla, con programas de

2 Imdosoc es una organización sin fines de lucro, fundada en 1983 en la Ciudad de México, con varios objetivos: promover los derechos humanos, la libertad de conciencia y de religión, así como la participación ciudadana y la solidaridad económica. 
salud y nutrición, de formación, de medio ambiente, de desarrollo agrario y de artesanías, de economía solidaria y de ahorro. Los antecedentes de estas cajas de ahorro se sitúan en Guerrero en los años ochenta, cuando bajo la forma jurídica de cooperativa ${ }^{3}$ se creó una caja de ahorro y crédito popular llamada "Esfuerzos Compartidos". Será hasta 2004 cuando la Fundación integre entre sus actividades el programa de cajas de ahorro. En el marco del Imdosoc se determinó que esa fundación resultaba un espacio idóneo para supervisar y acompañar algunas de las cajas de ahorro y actividades iniciadas con la mencionada cooperativa "Esfuerzos Compartidos", todo ello en un contexto nacional de controversia por denuncias de fraudes en cajas de ahorro y crédito, junto a la revisión de la Ley de Cooperativas y una nueva regulación de actividades de cajas de ahorro y crédito popular. Con motivo de este escenario nacional, se decidió rescatar y apoyar proyectos informales de cajas de ahorro, todas situadas en municipios de altos niveles de pobreza y marginación, con un marcado enfoque de género, etnia y cooperación comunitaria.

El proyecto "Cajas de ahorro" parte de la convicción de que las familias de escasos recursos e ingresos no solo quieren y pueden ahorrar, sino que lo hacen cuando tienen a su alcance organizaciones e instrumentos adaptados a sus particularidades. A partir del estímulo y sensibilización en una cultura del ahorro, se pretende concientizar a la población de los beneficios de dicha práctica y de su importancia para la generación de redes de seguridad frente a la pobreza. Mediante la capacitación, acompańamiento y asesoría en el emprendimiento de proyectos productivos, y una vez cubiertas necesidades de primera instancia, como la seguridad alimentaria de las familias socias, se les impulsa a desarrollar proyectos productivos acordes al entorno en el que operan, y que opten por un empleo o ingresos económicos que les permitan mejorar sus condiciones de vida.

En 2011, el proyecto contaba con 35 iniciativas $^{4}$ en Oaxaca, distribuidas en pequeñas localidades de diecisiete municipios, y otras cinco en cuatro municipios de Guerrero, con un total de 3910 asociados. Todas estas cajas se sujetaban a la supervisión, apoyo y vigilancia de la Fundación, articulándose como si de una cooperativa de ahorro y crédito popular se tratase. Así, cuen-

3 Para profundizar en el estudio de las primeras experiencias de cooperativismo de ahorro y crédito, se recomienda la lectura de los trabajos correspondientes a los casos de México (La Red de la Gente, 2012), Latinoamérica (González-Vega, 2012), Alemania y Europa central (Guinnane, 2012) o España (Martínez, 2003). En ellos se describen valiosas enseñanzas acerca de la participación de órdenes religiosas en la difusión de las cajas de ahorro, como instrumento de expansión del capital por la caridad y el trabajo (Noguer, 1912), aplicando el concepto de autoayuda ligado estrechamente a la persona y obra de Friedrich Wilhelm Raiffeisen (1818-1888), que dio lugar al modelo de cooperativa que actualmente es seguido por más de novecientas mil cooperativas organizadas en todo el mundo (Klein, 2009).

4 El funcionamiento y la organización de las cajas de ahorro se regula con los estatutos y directrices de la Ley de Ahorro y Crédito Popular de México (DOF, 2009). 
tan con sus correspondientes órganos de gestión (Comité de Administración), participación democrática (Asamblea General) y supervisión (Consejo de Vigilancia), si bien gracias a su carácter informal no están sujetas a las exigencias, costes y requisitos de supervisión de las instituciones bancarias. La Fundación da cobertura legal a las asociaciones formadas en las comunidades, que no deben superar los quinientos socios, según establece la Ley de Ahorro y Crédito Popular de México (DOF, 2009), y les brinda apoyo jurídico y legal por medio de la Junta de Asistencia Privada.

Esta experiencia constituye un valioso ejemplo entre las diversas iniciativas y proyectos de inclusión financiera informales y, en ocasiones, con enfoques alternativos que, bajo diferentes formas jurídicas o amparados tras otras organizaciones, actúan en México (Conde, 2000a; Rojas, 2012; La Red de la Gente, 2012). El objetivo principal del presente estudio es la descripción del proyecto de cajas de ahorro de la Fundación León XIII en México; para ello, en lo que sigue se ofrecen información primaria de su funcionamiento, de las características de sus beneficiarios y de su capacidad de ahorro.

\section{Origen de la información y metodología}

El estudio del proyecto de cajas de ahorro de la Fundación León XIII ${ }^{5}$ se completa con dos fuentes esenciales de información primaria — de corte cualitativo y cuantitativo-, que se detallan abajo y cuyos principales resultados se indican en los siguientes incisos:

a) Entrevistas en profundidad a actores clave. Durante noviembre y diciembre de 2012 se realizó un proceso de observación directa en las comunidades, aplicándose entrevistas en profundidad — se usó un cuestionario semiestructurado a modo de guión abierto- a cinco actores de la Fundación (director, asesora y promotora del proyecto, coordinador de zona y dos contables encargadas de formar, capacitar y dar seguimiento a las cajas de ahorro constituidas en las comunidades y de presentar los resultados trimestrales y anuales a la Junta de Asistencia Privada), así como a ocho socios de las cajas de distintas comunidades.

5 Agradecemos a los responsables y trabajadores de la Fundación León XIII que nos apoyaron en el desarrollo de esta investigación — participando en las entrevistas y aportándonos bases de datos disponibles de los socios de sus cajas de ahorro—, así como a los socios — entrevistados y encuestados—, por compartir su experiencia y conocimiento. Todos los técnicos de esta organización nos dieron su total apoyo para este estudio. 
b) Encuestas a socios. Los datos analizados aquí corresponden a los obtenidos con un cuestionario diseñado e implementado por trabajadores de la Fundación entre septiembre y diciembre de 2012. Dicho cuestionario contenía sesenta preguntas, con un primer bloque correspondiente a las características sociodemográficas de los socios y de su unidad familiar (nivel de estudios, edad, sexo, etc.), servicios del hogar y condiciones de vida (tipo de alojamiento, condiciones de habitabilidad del hogar y servicios de los que dispone la unidad familiar), principales fuentes de ingresos y actividad laboral desarrollada por la cabeza de familia, apoyos externos, prácticas agrarias y artesanales, y un último apartado en el que se solicitaba que los encuestados enumeraran los principales problemas de sus comunidades. Los datos obtenidos aportaron valiosa información de las condiciones de vida y niveles de bienestar de los socios de las cajas de ahorro y crédito, comprobándose la vulnerabilidad de la población beneficiaria de esta iniciativa de inclusión financiera. En el cuadro 1 se presenta la ficha técnica de la encuesta realizada, en cuyas últimas filas se aportan estadísticas oficiales — disponibles para los municipios en los que se realizaron las encuestas-, a modo de aproximación a los niveles de pobreza y vulnerabilidad de cada uno de ellos. Se obtuvieron 218 encuestas, en su mayoría con mujeres, socias de cajas de comunidades de diez localidades de cuatro municipios del estado de Oaxaca, lo que determina un error muestral adecuado para este tipo de estudios.

c) Información complementaria acerca de los socios encuestados. La información obtenida con la encuesta — garantizándose el anonimato y el análisis agregado de la información - se completó para 152 de las socias encuestadas con los datos que sobre sus niveles de ahorro disponía la Fundación, procedente de los registros que esta tenía para algunas de las localidades estudiadas. El objetivo de incorporar a los análisis de la encuesta realizada esta información era el de comprobar los niveles de ahorro anuales efectivos de cada uno de los encuestados, aspecto que no era tratado en el cuestionario implementado, el cual no contaba con registros de información para cubrir la totalidad de la muestra encuestada.

En el apartado de resultados, primero se describe la información obtenida en las entrevistas personales con actores clave, a modo de valoración del proyecto de cajas de ahorro. En segundo lugar, se presentan las principales conclusiones de la encuesta, caracterizándose a los socios del proyecto a partir de los análisis bivariantes realizados mediante el test X2 Pearson (o en su caso Test Exacto Fisher) y de diferencia de medias. La información de la capacidad de ahorro de cada socio (correspondiente a los ingresos mensuales de 2012) permitió su posterior clasificación en las cajas de ahorro, a partir del procedimiento de 
clúster o conglomerados y mediante el método de clasificación de $\mathrm{k}$ medias que proporciona el programa estadístico sPss-18. Los análisis aportan valiosa información que identifica a los socios según sus posibilidades de ahorro, ofreciendo una segmentación de los beneficiarios de este proyecto de ahorro e inclusión financiera informal, proporcionando, al mismo tiempo datos cuantitativos del potencial de ahorro que posibilita este proyecto.

Cuadro 1. Ficha técnica de la encuesta a socios

\begin{tabular}{|c|c|c|c|c|c|c|}
\hline & \multicolumn{6}{|c|}{ Estado de Oaxaca (México) } \\
\hline 4 municipios & \multicolumn{6}{|c|}{ Santiago Pinotepa Nacional, San Pedro Amuzgos, San Pedro Jicayán y Santo Domingo } \\
\hline 10 comunidades & \multicolumn{6}{|c|}{$\begin{array}{l}\text { Santiago Pinotepa Nacional, Lo de Candela, Lo de Mejía, El Ciruelo, Guadalupe Victoria, Los } \\
\text { Horcones, San Juan, San Pedro Amuzgos, Chuparrosa y Santo Domingo Armenta }\end{array}$} \\
\hline Universo & \multicolumn{6}{|c|}{ Población mayor de edad, socias(os) del proyecto de cajas de ahorro } \\
\hline Tamaño muestral & \multicolumn{6}{|c|}{218 encuestas } \\
\hline Error $(50 / 50)$ & \multicolumn{6}{|c|}{ $\pm 6.77 \%$ proporciones intermedias } \\
\hline Error (10/90) & \multicolumn{6}{|c|}{ $\pm 4.06 \%$ proporciones extremas } \\
\hline Nivel de confianza & \multicolumn{6}{|l|}{$95 \%(k=2)$} \\
\hline Trabajo de campo & \multicolumn{6}{|c|}{ Septiembre y octubre de 2012} \\
\hline \multicolumn{7}{|c|}{ Promemoria* - Estadísticas de pobreza y vulnerabilidad } \\
\hline \multicolumn{2}{|c|}{$\begin{array}{l}\text { Índices y porcentaje de población/ } \\
\text { municipios estudiados } \\
\text { del estado de Oaxaca }\end{array}$} & $\begin{array}{l}\text { Santiago } \\
\text { Pinotepa } \\
\text { Nacional }\end{array}$ & $\begin{array}{l}\text { Santo Domin- } \\
\text { go Armenta }\end{array}$ & $\begin{array}{l}\text { San Pedro } \\
\text { Amuzgos }\end{array}$ & $\begin{array}{l}\text { San Pedro } \\
\text { Jicayán }\end{array}$ & $\begin{array}{l}\text { Estado } \\
\text { Oaxaca }\end{array}$ \\
\hline \multicolumn{2}{|c|}{ Ingreso per cápita (\$USA PPC) } & 5437 & 3472 & 3063 & 2556 & 4746 \\
\hline \multicolumn{2}{|c|}{ Índice de Desarrollo Humano } & $0.761^{\text {Medio }}$ & $0.697^{\text {Medio }}$ & $0.692^{\text {Medio }}$ & $0.662^{\text {Medio }}$ & $0.747^{\text {Medio }}$ \\
\hline \multicolumn{2}{|c|}{ Índice de Rezago SocialGrado } & $0.344^{\text {Medio }}$ & $0.823^{\text {Alto }}$ & $1.050^{\text {Alto }}$ & $1.496^{\text {Alto }}$ & $0.768^{\text {Muy alto }}$ \\
\hline \multicolumn{2}{|c|}{ Índice de MarginaciónGrado } & $0.318^{\text {Medio }}$ & $1.211^{\text {Muy Alto }}$ & $0.870^{\text {Alto }}$ & $1.623^{\text {Muy Alto }}$ & $0.652^{\text {Alto }}$ \\
\hline \multicolumn{2}{|c|}{ (\%) En situación de pobreza } & 73.26 & 89.73 & 86.95 & 86.00 & 67.20 \\
\hline \multicolumn{2}{|c|}{ (\%) Pobreza moderada } & 43.58 & 40.51 & 37.47 & 32.74 & 40.50 \\
\hline \multicolumn{2}{|l|}{ (\%) Pobreza extrema } & 29.68 & 49.23 & 49.48 & 53.26 & 26.60 \\
\hline
\end{tabular}

* Fuente: Coneval (2012), Conapo (2012) y PNUD México (2008)

\section{Resultados y discusión}

\section{Aproximación cualitativa al proyecto de cajas de ahorro}

Los actores clave del proyecto entrevistados plantearon que uno de los momentos más importantes en la creación de una caja de ahorro es la llegada de la Fundación a una nueva comunidad. Lo primero es superar la desconfianza que en general se tiene por este tipo de instrumento, originada muchas veces por situaciones previas de fraude y estafa asociados a las cajas de ahorro rurales. Son tres las maneras en que la Fundación realiza el contacto inicial con las comunidades; 
se las enlista por orden de preferencia y de vital importancia para el posterior desarrollo de la iniciativa:

1) a través de la recomendación de comunidades vecinas (lo solicita la comunidad interesada en el proyecto de ahorro);

2) por invitación de personas relevantes en la comunidad (representante municipal, sacerdotes, maestros, etc.);

3) por iniciativa de la propia Fundación, una vez identificadas las comunidades con desventajas socioeconómicas graves que las determinan como potenciales destinatarias de expansión del proyecto (de menos de tres mil habitantes en desventaja social, elevada tasa de desnutrición infantil o situación conflictiva).

Una excepción (pues supera los tres mil habitantes) es la ciudad de Santiago Pinotepa Nacional. La razón de que se opere en esta localidad es porque allí se encuentra la oficina de la Fundación León XIII en Oaxaca y es allí donde se inició la actividad en un primer momento.

Un reto suele ser la capacidad de la organización para trabajar con comunidades indígenas (tlapanecas, mixtecas, nahuas, amuzgas o afromestizos), pues existe una barrera integrada por su lengua, su "visión del mundo" y las condiciones de desventaja históricas que aún enfrenta la población indígena en México (Mikkelsen, 2014: pp. 70-81), lo que complejiza el acercamiento a esas comunidades, aunque ello se supera más fácil cuando existen relaciones previas o comunidades "espejo" cercanas, donde la Fundación ya realiza actividades, lo que muestra su intención de establecer un vínculo con las comunidades estable y constante en el tiempo.

No conviene olvidar, como señalan Álvarez et al. (2011), la importancia que en la intervención de cualquier proyecto de desarrollo - como es el de inclusión financiera en los estados del sur de México- tiene la consideración y comprensión de todas las dimensiones culturales, sociales, organizacionales o educativas de la población con la que se interactúa. Así, en los territorios donde opera la Fundación León XIII — distintas comunidades rurales de tres estados-, coexisten múltiples culturas con diferencias en su interior que, ante los cuantiosos cambios e influencias debidas a la globalización económica y cultural de las últimas décadas, responden a un modelo de "mestizaje" e "hibridación", descrito en diversos procesos culturales por García Canclini (2001).

En las charlas iniciales destinadas a la organización de grupos en cada comunidad, se plantean los tres aspectos esenciales del funcionamiento de una caja de ahorro: 
a) la periodicidad (anual) del "esfuerzo del ahorro", siempre voluntario y semanal;

b) la permanencia en la comunidad de los ahorros;

c) y la remuneración del ahorro.

Estos elementos luego se amplían a partir de los comentarios recabados en las entrevistas mantenidas con responsables y trabajadores del proyecto:

a) "Las cajas se liquidan anualmente para que no se acumule el capital y no represente un riesgo para la gente custodiar el efectivo y para no generar problemas fiscales. Además, la gente pobre tiene muchas necesidades como para estar acumulando dinero, por lo que se les asesora para que inviertan en alguna actividad productiva, en aquello que pueda mejorar sus condiciones de vida".

b) El dinero siempre "se queda en las comunidades, siendo el Comité de Administración el encargado de custodiarlo”. La evolución de los ahorros y los créditos se presentan a los asociados cada tres meses, y en diciembre de cada ańo se realiza la liquidación a cada socio.

c) El interés concedido a los ahorros de cada caja "son variables, dependiendo de los ingresos obtenidos por los préstamos realizados durante el año en cada una de las cajas de cada comunidad" o, en algunos casos, las rentabilidades obtenidas por el depósito de los ahorros en alguna entidad financiera formal cuando existen en la misma localidad.

Para iniciar la actividad en una comunidad es necesario un mínimo de diez socias(os), primándose la formación de cajas a partir de mujeres; es esencial —en opinión de los responsables y técnicos entrevistados - el acompañamiento y las directrices de la Fundación para la formación de los socios. La capacitación que aquella brinda a las comunidades incluye cursos de formación en administración, cooperativismo, economía solidaria y comercio justo, a los que adicionalmente se unen otros de elaboración de proyectos productivos y planes de negocio, educación en valores éticos — siguiendo la doctrina de la Iglesia católica-, o talleres: de artesanías, medicina natural, agricultura y ganadería, en el marco de los distintos programas que desarrolla en las zonas donde interviene.

En las primeras semanas, por votación a mano alzada (un voto una persona) se forma el Comité de Administración, integrado por cinco miembros: una(un) presidenta, una(un) secretaria(o), una(un) tesorera(o) y dos auxiliares. Ellos ocuparán el cargo por tres años, aunque cada año cualquiera de sus miembros puede ser revocado por la Asamblea General "si no han cumplido cabalmente con su responsabilidad". 
La renovación de cargos y responsabilidades contempla que los integrantes del Comité de Administración salientes pueden pasar a formar parte del Comité de Vigilancia, encargado de "preservar el cumplimiento de los estatutos o de apoyar y asesorar al nuevo comité en la correcta administración de la caja”. Desde el momento en que se constituye el Comité de Administración, y previo pago de una cuota de inscripción de 25 pesos, todos los socios que así lo deseen podrán ahorrar cada semana, en el día y hora señalados por ese comité y por acuerdo de la Asamblea General.

La entrada de nuevos socios es valorada y autorizada por el Comité de Administración; en un primer momento "no se excluye a nadie, pero el sistema de cajas de ahorro se basa en la confianza y el conocimiento entre las personas", por lo que la decisión final de incluir o no a una(un) socia(o) depende de la decisión de dicho Comité.

La labor de vigilancia y supervisión de la Fundación es permanente, si bien ocasionalmente ha debido actuar más allá de las labores de asesoramiento, acompañamiento y capacitación que regularmente cumple. Un aspecto externo crítico en el desarrollo de las cajas tiene que ver con la situación de inseguridad y el alto índice de criminalidad imperante en el país. Este supone la asunción por parte del Comité de Administración de un riesgo en la custodia y desplazamiento del dinero de los grupos, respondiendo de manera solidaria ante posibles incidencias.

\section{A. Visión de los responsables.}

La aceptación y evolución de los resultados del programa cajas de ahorro en los últimos ańos es un hecho que "complace y entusiasma" a los responsables del proyecto entrevistados. Han crecido cuantitativa y cualitativamente, e integrado elementos importantes para el desarrollo de las comunidades donde actúa el proyecto: "salud, educación, proyectos agropecuarios y el sentimiento religioso". En relación con este último aspecto, para ellos la referencia de Cristo — - según las propias palabras del responsable entrevistado - "es la respuesta a todas las incógnitas que surgen de lo cotidiano..., que les empuja a luchar contra los males, afirmando que no es lo mismo ser pobre que ser pobre sin la riqueza del evangelio. Este te aparta de los vicios, de la pérdida de valores como la solidaridad, la cooperación".

Entre las perspectivas y retos futuros, los responsables entrevistados indican la necesidad de seguir impactando en las comunidades, invertir para mejorar la calidad de vida de las familias y crecer tanto como la capacidad de que dispongan para organizar a las comunidades y que, mediante este proceso educativo, fortalezcan su organización a través de la capacitación, acompañamiento 
y seguimiento de la Fundación. La supervisión de las cajas es considerada una labor clave, ya que si se la descuida se puede generar el "espacio para el engaño, para que no se hagan y registren las cosas correctamente". Al ser un sistema de cajas de ahorro basado en la confianza y la solidaridad entre sus integrantes, depende de la vigilancia, de la supervisión y de la formación que se dé a los socios para que funcione adecuadamente, no permitiéndose "carteras perdidas" ni desfalcos.

Para los próximos años, el objetivo es crecer en cantidad y calidad, llegar a contar con cien cajas para finales de 2013, formar y capacitar a nuevas personas, y fortalecer los valores de colaboración y confianza dentro de las comunidades, siendo - en palabras de uno de los entrevistados_ " "prudentes en evitar la dependencia y el paternalismo. No es lo mismo dependencia que vinculación”.

\section{B. Visión de los trabajadores.}

En opinión de las trabajadoras de la Fundación entrevistadas, las cajas de ahorro se valoran como un instrumento "necesario y útil para el desarrollo de las familias y de sus comunidades". A través del acompañamiento en el proceso, y de las formaciones y capacitaciones que imparten, "los socios cambian la forma de ver las finanzas, aprenden a ahorrar y se les asesora para que inviertan en alguna actividad productiva" mejorando sus condiciones de vida personal, familiar y comunitaria. Además señalan que el acompañamiento reconforta y apoya a los socios, con lo que perciben nuevas oportunidades para ellos dentro y fuera de sus comunidades.

La mayor dificultad que se enfrenta en la constitución de una nueva caja es la desconfianza de las personas debida a malas experiencias relacionadas con las finanzas populares y fraudes, en las que han perdido todos sus ahorros; también "incide el trabajar con comunidades indígenas, ya que su forma de ver e interpretar el mundo es distinta". Destacan "la fuerza que les infunde" estar amparados por la religión católica para llegar a los socios y entrar en las comunidades. Los valores que la rigen y que defiende, tales como la honestidad, la solidaridad o la fraternidad, "inspiran confianza y seguridad" a los socios y constituye una vía de acercamiento eficaz.

En cuanto al seguimiento de los cursos y talleres impartidos, los entrevistados dicen percibir interés por parte de los socios "pero a la hora de tener que asistir es frecuente el uso de pretextos para no hacerlo y se justifican en la necesidad de atender a los hijos, a los nietos o en la distancia y tiempo necesarios para desplazarse desde sus comunidades". A pesar de ello, destacan que, con base en los resultados, el programa de cajas de ahorro demuestra ser "un gran apoyo", que contribuye a mejorar las condiciones de vida personal, familiar y comunitaria de los socios, y que como la liquidación es anual, ven recompensados sus esfuerzos y eso "les motiva para seguir ahorrando". 


\section{Visión de los beneficiarios.}

Prácticamente todos los entrevistados beneficiarios del proyecto coinciden en identificar las razones que los llevaron a decidirse a formar parte del mismo. La mayor motivación fue el ahorro y lo que este significaba: "poder hacer frente a sus necesidades", "a una emergencia", "prever gastos e incluso poder invertirlos a final de año en aquello que consideraran oportuno". Además, a esto se une la posibilidad de pedir préstamos y financiar distintas actividades a bajo interés. Entre las dudas que asaltaban a socias y socios al momento de incorporarse y formar parte del proyecto, la más repetida fue "si éste funcionaría bien", y "si recuperarían su dinero a final de año". Por el contrario, algunos de los socios entrevistados afirmaron "no tener dudas de ello a pesar de los comentarios que previamente pudieron escuchar acerca de proyectos de cajas anteriores". La "confianza en los integrantes de la misma", el "derecho a elegir bajo votación pública" a quienes formarán el Comité de Administración, la "liquidación anual" de los beneficios, así como la "necesidad de ahorrar", fueron para muchos de los entrevistados argumentos suficientes para constituir la caja en su comunidad, afrontando por ello su riesgo inherente. Muchos han sido los beneficios derivados de este programa, tantos como familias que lo integran; los más citados entre los socios entrevistados han sido el que a través del ahorro y del crédito han podido: "afrontar deudas", "mejorar la vivienda y la alimentación familiar", "invertir en la educación de sus hijos", hacer previsiones de gastos, enfrentar imprevistos e infortunios, invertir en actividades agrícolas y ganaderas e incluso "emprender otro tipo de actividades productivas" abriendo una nueva vía de ingresos familiares. Otro de los beneficios destacados es el aumento de la "concienciación en la necesidad y los beneficios del ahorro".

La valoración general por parte de las(os) socias(os) es positiva, lo que manifiesta que este proyecto contribuye a su desarrollo personal y comunitario. Afirman "recomendarla a familiares y vecinos" por ser una excelente vía para lograr un mayor control de sus ingresos, y por el "buen funcionamiento" de las cajas. Valoran positivamente el asesoramiento y acompańamiento recibido desde la Fundación en el desarrollo de nuevos proyectos productivos y de seguridad alimentaria, y en todos los procesos que inician, además de que con los talleres aumentan las capacidades y habilidades con las que enfrentan su realidad.

Como señala Conde (2000b), estas y otras modalidades de ahorro comunitario fuera del sistema financiero, se tornan frágiles cuando se crean autónomamente — sin el acompañamiento de una organización de confianza y que trabaja en el territorio de manera permanente que las supervisa, acompaña y capacita-, lo que ayuda a entender la dimensión que ha alcanzado este proyecto, valorado muy positivamente por sus usuarios y en expansión a otras comunidades. 
En este apartado se presentan los datos más destacados de la encuesta realizada a socios del proyecto de cajas de ahorro, señalada en el epígrafe metodológico. Se comienza con la descripción de las variables sociodemográficas y las condiciones de vida de los beneficiarios de este proyecto, para después exponer un análisis de la caracterización de la capacidad de ahorro de los socios encuestados.

\section{A. Caracterización de los socios.}

La mayor parte de las personas encuestadas eran socias(os) de cajas de ahorro ubicadas en Santiago Pinotepa Nacional y Santo Domingo Armenta, los dos municipios en estudio donde la Fundación cuenta con un mayor número de asociados. En el primer caso, son trece cajas en diferentes localidades, creadas entre 1996 y 2011, con 1343 personas asociadas; y en el segundo, una sola caja fundada en 1997, actualmente con quinientos socios.

Las cuatro cajas estudiadas en San Pedro Amuzgos eran de más reciente creación (2010 y 2011), con un total de 117 socios; mientras que las tres cajas del municipio de San Pedro Jicayán sumaban 142 asociados.

La mayoría de los socios encuestados fueron mujeres (92.20\%), en tanto que las lenguas vehiculares más frecuentes fueron el español (65.60\%), el mixteco (21.56\%) y el amuzgo (12.84\%). La clasificación de los socios atendiendo a esta última variable, permitió comprobar diferencias significativas entre los socios.

Como se observa en el cuadro 2 , es mayor el porcentaje de alfabetizados entre quienes su lengua materna era el español que entre quienes provienen de los pueblos antes señalados. Si bien para el conjunto de la muestra cerca de un $57 \%$ contaba con menos de seis años de escolaridad, en el caso de indígenas ese porcentaje aumenta casi diez puntos.

El mayor rezago de los grupos étnicos descritos se comprueba de nuevo en lo que se refiere a niveles de renta, donde se encontró que el ingreso mensual de los hogares para un $73 \%$ de la muestra era entre los 0 y los 999 pesos, con $7 \%$ de los hogares con ingresos mayores a los dos mil pesos.

La principal actividad productiva de los encuestados es la agricultura y la ganadería, con $77.06 \%$ de los jefes de familia campesinos, y $91.28 \%$ de las madres dedicadas a las tareas del hogar y al cuidado de los hijos. En casi la mitad de los hogares encuestados, la tenencia de la tierra era ejidal, seguida en importancia por tierras arrendadas y en propiedad.

Un $81.65 \%$ indicó que se dedicaba a la actividad agraria de autoconsumo, y el resto destinaba parte de su producción a la venta en mercados locales; las producciones más frecuentes son el frijol, el maíz y el chile, seguidas de otras producciones hortícolas. 
Cuadro 2. Caracterización del socio atendiendo a su origen étnico (218)

\begin{tabular}{|c|c|c|c|c|}
\hline \multirow{2}{*}{ Frecuencia relativa (\%) } & & \multicolumn{3}{|c|}{ Lengua materna } \\
\hline & & Español & Indígena & Total \\
\hline \multirow{4}{*}{ Municipio ${ }^{1}$} & Santiago Pinotepa Nacional & 65.73 & 16.00 & 48.62 \\
\hline & Santo Domingo Armenta & 33.57 & 1.33 & 22.48 \\
\hline & San Pedro Amuzgos & 0.70 & 36.00 & 12.84 \\
\hline & San Pedro Jicayán & 0.00 & 46.67 & 16.06 \\
\hline \multirow{3}{*}{ Edad $^{2}$} & $<35$ años & 30.28 & 41.89 & 34.26 \\
\hline & $36-50$ años & 35.21 & 32.43 & 34.26 \\
\hline & $>51$ años & 34.51 & 25.68 & 31.48 \\
\hline \multirow{2}{*}{ Alfabetizados ${ }^{3}$} & Sí & 86.71 & 73.33 & 82.11 \\
\hline & No & 13.29 & 26.67 & 17.89 \\
\hline \multirow{6}{*}{ Estudios $^{4}$} & 0-3 años primaria & 18.88 & 22.67 & 20.18 \\
\hline & 0-6 años primaria & 32.87 & 44.00 & 36.70 \\
\hline & Secundaria & 23.08 & 13.33 & 19.72 \\
\hline & Preparatoria & 6.99 & 1.33 & 5.05 \\
\hline & Otros & 3.50 & 4.00 & 3.67 \\
\hline & NS/NC & 14.69 & 14.67 & 14.68 \\
\hline \multirow{5}{*}{ Renta del hogar ${ }^{5}$} & $0-999 \$$ & 66.43 & 88.67 & 73.39 \\
\hline & $1000-1999 \$$ & 24.48 & 10.67 & 19.72 \\
\hline & $2000-2999 \$$ & 5.59 & 1.33 & 4.13 \\
\hline & $3000-3999 \$$ & 2.10 & 1.33 & 1.83 \\
\hline & $>4000 \$$ & 1.40 & 0.00 & 0.92 \\
\hline Renta media del hogar* & $\$=$ pesos mexicanos & 975.52 & 673.33 & 871.56 \\
\hline Renta media $\mathrm{pc}^{\star}$ & $\$=$ pesos mexicanos & 285.69 & 151.15 & 239.44 \\
\hline \multirow{2}{*}{ Tiene tierra ${ }^{6}$} & Sí & 48.94 & 66.67 & 55.09 \\
\hline & No & 51.06 & 33.33 & 44.91 \\
\hline \multirow{2}{*}{ Problemas comunidad ${ }^{7}$} & 1 o más problemas & 68.53 & 68.00 & 68.35 \\
\hline & Sin problemas o NS/NC & 31.47 & 32.00 & 31.65 \\
\hline \multirow{2}{*}{ Recibe apoyos públicos ${ }^{8}$} & Sí & 92.31 & 92.00 & 92.20 \\
\hline & No & 7.69 & 8.00 & 7.80 \\
\hline
\end{tabular}

${ }^{1} x^{2}=162.232 a=0.000 ;{ }^{2} x^{2}=3.229 a=0.199 ;{ }^{3} x^{2}=5.996 a=0.014 ;{ }^{4} x^{2}=7.536 a=0.184 ;{ }^{5} x^{2}=10.870 a=0.028 ; 6 x^{2}=6.221$ $a=0.013 ;{ }^{7} x^{2}=0.006 a=0.936 ;{ }^{8} x^{2}=0.006 a=0.936$.

Fuente: Elaboración propia a partir de los datos de la encuesta.

Un alto porcentaje de los encuestados cuenta con ganado en su hogar (72.48\%), oscilando el número promedio de animales de los que disponen las familias entre cinco y diez para gallinas, reses y conejos, y entre tres y cinco cabezas de cerdos, borregos y cabras.

Para muchos de los encuestados, la venta de artesanías representa un recurso que contribuye al ingreso familiar; $25.46 \%$ de los casos indicaron venderlas en sus comunidades, con la actividad textil como la más extendida (19.27\%), y en menor medida la alfarería, la palma o la producción de alimentos.

En otras variables, las diferencias entre grupos étnicos no resultaron significativas. Así fue con el porcentaje de hogares que recibe apoyos públicos o la 
consideración por parte de los encuestados de que en sus localidades no hay problemas graves. Los apoyos se reciben en la mayoría de los hogares (92\%), fundamentalmente a través de programas sociales promovidos por el gobierno, como Oportunidades (67.89\%), Seguro Popular (61.93\%), Pro Campo (17.43\%), 1 kg de Ayuda (11.01\%) o 70 y Más (7.80\%).

A la pregunta de qué problemas identificaban como principales en su localidad, los socios de los cuatro municipios señalaron algunos comunes: carestía de agua potable, falta de energía eléctrica y alumbrado público, calles en mal estado o no pavimentadas, desempleo y división política. Otros eran la falta de recogida y tratamiento de basuras, falta de servicios médicos en las comunidades, escuelas en mal estado, la falta de un mercado local para vender las artesanías y productos agrícolas, o la inseguridad.

B. Condiciones de vida y pobreza material de los socios.

La caracterización de los socios del proyecto del apartado precedente, se completa en este con un análisis de sus condiciones de vida, a partir del estudio de variables relativas a los métodos de construcción de sus viviendas, los servicios básicos que se suministran o los bienes con los que cuentan en sus hogares.

Cuadro 3. Dimensiones de pobreza en los hogares de los socios (218)

\begin{tabular}{|c|c|c|c|c|c|c|c|c|}
\hline \multirow{2}{*}{\multicolumn{2}{|c|}{ Frecuencia relativa (\%) }} & \multicolumn{3}{|c|}{ Lengua materna* } & \multicolumn{4}{|c|}{ Renta p.c. familiar ${ }^{\star *}$} \\
\hline & & Español & Indígena & Total & Baja & Media & Alta & Total \\
\hline \multirow{4}{*}{$\begin{array}{l}\text { Material de } \\
\text { la casa }^{1}\end{array}$} & Adobe & 23.08 & 76.71 & 41.20 & 46.56 & 36.62 & 14.29 & 41.20 \\
\hline & Tabique & 55.94 & 17.81 & 43.06 & 37.40 & 52.11 & 50.00 & 43.06 \\
\hline & Ladrillo & 16.08 & 0.00 & 10.65 & 9.16 & 9.86 & 28.57 & 10.65 \\
\hline & Otro & 4.90 & 5.48 & 5.10 & 6.87 & 1.41 & 7.14 & 5.10 \\
\hline \multirow{2}{*}{$\begin{array}{l}\text { Suelo de } \\
\text { cemento }^{2}\end{array}$} & Sí & 91.61 & 70.67 & 84.40 & 77.44 & 94.37 & 100.00 & 84.40 \\
\hline & No & 8.39 & 29.33 & 15.60 & 22.56 & 5.63 & 0.00 & 15.60 \\
\hline \multirow{3}{*}{$\begin{array}{l}\text { Material } \\
\text { del techo }\end{array}$} & Lámina & 50.00 & 50.67 & 50.24 & 51.91 & 53.03 & 21.43 & 50.24 \\
\hline & Colado & 30.15 & 10.67 & 23.22 & 17.56 & 25.76 & 64.29 & 23.22 \\
\hline & Otro & 19.86 & 38.66 & 26.54 & 30.53 & 21.22 & 14.28 & 26.54 \\
\hline \multirow{4}{*}{$\begin{array}{l}\text { Tipo de } \\
\text { baño }^{4}\end{array}$} & Fosa séptica & 62.94 & 37.33 & 54.13 & 54.14 & 53.52 & 57.14 & 54.13 \\
\hline & Red pública & 21.68 & 2.67 & 15.14 & 12.78 & 18.31 & 21.43 & 15.14 \\
\hline & Letrina & 9.09 & 48.00 & 22.48 & 24.81 & 18.31 & 21.43 & 22.48 \\
\hline & Otro & 6.29 & 12.00 & 8.26 & 8.27 & 9.86 & 0.00 & 8.26 \\
\hline \multirow{3}{*}{ Agua $^{5}$} & Entubada & 77.14 & 48.00 & 66.98 & 61.07 & 77.14 & 71.43 & 66.98 \\
\hline & Acarreada & 13.57 & 48.00 & 25.58 & 30.53 & 17.14 & 21.43 & 25.58 \\
\hline & Pozo & 9.29 & 4.00 & 7.44 & 8.40 & 5.71 & 7.14 & 7.44 \\
\hline \multirow{2}{*}{$\begin{array}{l}\text { Tiene } \\
\text { frigorífico }\end{array}$} & Sí & 93.71 & 70.67 & 85.78 & 81.95 & 90.14 & 100.00 & 85.78 \\
\hline & No & 6.29 & 29.33 & 14.22 & 18.05 & 9.86 & 0.00 & 14.22 \\
\hline \multirow{2}{*}{ Tiene TV ${ }^{7}$} & Sí & 92.31 & 57.33 & 80.28 & 75.19 & 87.32 & 92.86 & 80.28 \\
\hline & No & 7.69 & 42.67 & 19.72 & 24.81 & 12.68 & 7.14 & 19.72 \\
\hline
\end{tabular}


Cuadro 3. Dimensiones de pobreza en los hogares de los socios (218) (Continuación)

\begin{tabular}{lcccccccc}
\hline \multirow{2}{*}{ Frecuencia relativa (\%) } & \multicolumn{3}{c}{ Lengua materna* $^{*}$} & \multicolumn{4}{c}{ Renta p.c. familiar $^{* *}$} \\
\cline { 3 - 9 } & & Español & Indígena & Total & Baja & Media & Alta & Total \\
\hline \multirow{2}{*}{ Tiene } & Sí & 27.97 & 13.33 & 22.94 & 18.80 & 30.99 & 21.43 & 22.94 \\
radio $^{8}$ & No & 72.03 & 86.67 & 77.06 & 81.20 & 69.01 & 78.57 & 77.06 \\
\hline \multirow{2}{*}{ Tiene } & Sí & 16.90 & 1.33 & 11.52 & 6.77 & 15.71 & 35.71 & 11.52 \\
coche $^{9}$ & No & 83.10 & 98.67 & 88.48 & 93.23 & 84.29 & 64.29 & 88.48 \\
\hline & Total & 100.0 & 100.0 & 100.0 & 100.0 & 100.0 & 100.0 & 100.0
\end{tabular}

* Lengua materna: ${ }^{1}\left(X^{2}=63.29 ; a=0.000\right) ;{ }^{2}\left(X^{2}=16.39 ; a=0.000\right) ;{ }^{3}\left(X^{2}=24.43 ; a=0.000\right) ;{ }^{4}\left(X^{2}=52.78 ; a=0.000\right) ;{ }^{5}\left(X^{2}=30.66\right.$; $a=0.000) ;{ }^{6}\left(x^{2}=21.41 ; a=0.000\right) ;{ }^{7}\left(x^{2}=38.01 ; a=0.000\right) ;{ }^{8}\left(x^{2}=5.97 ; a=0.015\right) ;{ }^{9}\left(x^{2}=11.67 ; a=0.001\right)$.

** Renta per cápita: ${ }^{1}\left(X^{2}=20.36 ; a=0.009\right) ;{ }^{2}\left(X^{2}=12.83 ; a=0.002\right) ;{ }^{3}\left(X^{2}=21.37 ; a=0.019\right) ;{ }^{4}\left(X^{2}=3.61 ; a=0.729\right) ;{ }^{5}\left(X^{2}=5.55\right.$; $a=0.236) ;{ }^{6}\left(X^{2}=5.02 ; a=0.081\right) ;{ }^{7}\left(X^{2}=5.80 ; a=0.055\right) ;{ }^{8}\left(X^{2}=3.91 ; a=0.142\right) ;{ }^{9}\left(X^{2}=12.20 ; a=0.002\right)$.

Fuente: Elaboración propia a partir de los datos de la encuesta.

Nuevamente, el origen indígena de los entrevistados identifica peores condiciones de vida (cuadro 3). Así, en este este grupo se halló un mayor porcentaje de hogares con viviendas de peores condiciones (paredes de adobe, suelo de barro y techos de colado), sin servicios públicos (de abastecimiento de agua o de saneamiento), o sin bienes (televisión, radio, coche). Al margen de esas diferencias, cabe recordar las carencias que en general tienen todos los socios de las cajas encuestados, en términos de altos porcentajes, por ejemplo, de viviendas de adobe (41.20\%), sin piso de cemento (15.60\%), que deben acarrear el agua para consumo en el hogar $(25.58 \%)$, que carecen de un vehículo (88.48\%) o de televisión (19.72\%).

De igual modo, la clasificación de la renta per cápita de los encuestados en tres niveles (baja, media y alta), posibilita observar diferencias significativas $(\alpha<0,05)$ entre los socios de las cajas. Así, se comprueba la existencia de una relación significativa tal que, a mayores niveles de renta per cápita se corresponden mejores condiciones de vida debido a más calidad de los materiales de construcción de la vivienda (paredes, suelo y techo), ser receptores de servicios públicos de saneamiento o disponer en el hogar de bienes básicos, como un frigorífico.

\section{Capacidad de ahorro de los beneficiarios.}

La capacidad de ahorro media final de los socios encuestados en comunidades para los que se contaba con información de sus depósitos (152 casos), fue de 4814 pesos mexicanos por cada uno de esos socios, con una mediana de esa cifra de 2175 pesos. Si bien cada ańo se liquida a cada socio el total de sus ahorros, esos montos son en muchas ocasiones fruto acumulado desde que cada socio se afilió a sus respectivas cajas de ahorro. Por lo tanto, pese a los escasos ingresos familiares de la mayor parte de los socios, la capacidad de ahorro anual (o acumulado) que este proyecto de cajas posibilita es considerable, por lo que, en ese sentido, esta experiencia de inclusión financiera informal es muy valiosa. 
Como era de esperarse, el porcentaje de socios con altos niveles de ahorro aumenta conforme el socio dispone de una mayor renta familiar y depende menos de apoyos externos; lo que disminuye entre socios cuando la lengua materna es indígena o pertenecen a los dos municipios (San Pedro Amuzgos y San Pedro Jicayán) con menores niveles de renta según las cifras oficiales y un mayor porcentaje de personas en situación de pobreza extrema.

Cuadro 4. Clasificación de los socios (152)

\begin{tabular}{|c|c|c|c|c|c|}
\hline \multicolumn{2}{|c|}{ Clústers (C) identificados } & C1 & C2 & C3 & Total \\
\hline \multicolumn{2}{|c|}{ Distribución de socios (\%) } & $(34.21)$ & $(43.42)$ & $(22.37)$ & 100.00 \\
\hline \multicolumn{2}{|c|}{ Variables consideradas (\%) } & C1 & $\mathrm{C} 2$ & $\mathrm{C} 3$ & Total \\
\hline \multirow{4}{*}{ Municipio ${ }^{1}$} & Santiago Pinotepa Nacional & 57.69 & 71.21 & 0.00 & 50.66 \\
\hline & Santo Domingo Armenta & 42.31 & 28.79 & 0.00 & 26.97 \\
\hline & San Pedro Amuzgos & 0.00 & 0.00 & 47.06 & 10.53 \\
\hline & San Pedro Jicayán & 0.00 & 0.00 & 52.94 & 11.84 \\
\hline \multirow{2}{*}{ Etnia $^{2}$} & Español & 90.38 & 92.42 & 0.00 & 71.05 \\
\hline & Indígena & 9.62 & 7.58 & 100.00 & 28.95 \\
\hline \multirow{3}{*}{ Edad $^{3}$} & $<35$ años & 0.00 & 45.45 & 35.29 & 27.63 \\
\hline & 36-50 años & 15.38 & 54.55 & 38.24 & 37.50 \\
\hline & >51 años & 84.62 & 0.00 & 26.47 & 34.87 \\
\hline \multirow{2}{*}{ Alfabetizados ${ }^{4}$} & Sí & 65.38 & 92.42 & 82.35 & 80.92 \\
\hline & No & 34.62 & 7.58 & 17.65 & 19.08 \\
\hline \multirow{3}{*}{$\begin{array}{l}\text { Renta p.c. del } \\
\text { hogar }^{5}\end{array}$} & Renta p.c. (Baja) & 32.69 & 71.21 & 73.53 & 58.55 \\
\hline & Renta p.c. (Media) & 51.92 & 22.73 & 26.47 & 33.55 \\
\hline & Renta p.c. (Alta) & 15.38 & 6.06 & 0.00 & 7.89 \\
\hline \multirow{4}{*}{ Ahorro 6} & $59-1275 \$$ & 13.46 & 21.21 & 85.29 & 32.89 \\
\hline & $1300-4500 \$$ & 26.92 & 48.48 & 14.71 & 33.55 \\
\hline & $4510-36400 \$$ & 59.62 & 30.30 & 0.00 & 33.55 \\
\hline & Ahorro medio (pesos) ${ }^{\star}$ & 7013.23 & 5305.66 & 703.41 & 4859.94 \\
\hline
\end{tabular}

${ }^{1}\left(x^{2}=155.02 ; a=0.000\right) ;{ }^{2}\left(x^{2}=107.560 ; a=0.000\right) ;{ }^{3}\left(X^{2}=95.186 ; a=0.000\right) ;{ }^{4}\left(x^{2}=13.832 . \quad a=0.001\right) ;{ }^{5}\left(X^{2}=23.752 ; a=0.000\right) ;$ ${ }^{6}\left(x^{2}=67.897 . a=0.000\right){ }^{*}$ Ftest: $(10.485 ; a=0.000)$ Distancia euclidiana: $(C 1-C 2=1.466) ;(C 1-C 3=2.863) ;(C 2-C 3=2.631)$. Fuente: Elaboración propia a partir de los datos de la encuesta y de la base de datos de la Fundación.

El agrupamiento de socios encuestados de los que se disponía de información de su nivel de ahorro a través de las cajas, atendiendo a distintas variables, llevó a la determinación de los tres clústers (C) que se describen en el cuadro 4. Este permite diferenciar a los beneficiarios de este proyecto, comprobando las desiguales capacidades de ahorro que existe entre los asociados si se atiende a sus características — renta, edad, etnia o localidad de origen-. De este modo, se han identificado tres tipologías de beneficiarios del proyecto de cajas de ahorro:

1) Grandes ahorradores. El primer clúster (C1), que agrupa a 52 encuestados, se conforma de asociados que en su mayoría tienen como lengua materna 
el español. Con un nivel de ahorro medio de casi siete mil pesos, es el grupo con el más elevado porcentaje de personas en los niveles de renta alta para la zona; todos son habitantes de comunidades de los dos municipios (Santiago Pinotepa Nacional y Santo Domingo Armenta) de mayores niveles de renta per cápita entre los casos estudiados. Este grupo, además, se caracteriza por integrarse por socios que en su mayor parte superan los 51 ańos (84.62\%) y — por su mayor edad— con las más elevadas tasas de analfabetismo.

2) Medianos ahorradores. La disimilaridad entre este (C2) y el anterior clúster (C1), medida a través de la distancia euclidiana, es la menor entre los grupos descritos. Se trata del grupo de mayor tamaño (66 socios), que agrupa a los que presentaron ahorros medios de 5302 pesos mexicanos, ligeramente superiores al dato medio total de la muestra. Pertenecientes a localidades de los dos municipios ya citados, son en su mayoría población no indígena, con edades inferiores a los 51 años - lo que está relacionado con su menor nivel de analfabetismo-. Predomina, en este caso, la pertenencia del socio encuestado al grupo de renta per cápita más baja (71.21\%).

3) Pequeños ahorradores. Este clúster (C3) agrupa a los socios encuestados (34) que reportan la menor capacidad de ahorro (730 pesos de media). Son en su totalidad de etnia indígena y pertenecen a comunidades de los dos municipios con menores niveles de renta (San Pedro Amuzgos y San Pedro Jicayán) y los mayores niveles de pobreza extrema y rezago social, lo que apunta a la relación directa esperada entre bajos niveles de renta o la condición indígena de la población con una inferior capacidad de ahorro.

\section{Conclusión}

Las iniciativas de ahorro y crédito popular en los países en desarrollo cumplen un papel destacado en la lucha contra la exclusión financiera que vive gran parte de las personas de más bajos ingresos. Esa situación, descrita para el caso de México, afecta gravemente a la población rural, o a segmentos especialmente vulnerables, como las mujeres o los indígenas. Para contribuir a romper esas barreras que impiden el acceso a servicios financieros, surgen en distintas partes del mundo iniciativas de organizaciones para mitigar esa situación buscando mejorar una situación de pobreza. En la introducción de este trabajo se han descrito algunas — públicas o privadas— que se han implementado en México en la última década.

En ese contexto se ha presentado el proyecto de cajas de ahorro informales que emprendió en México hace más de una década la Fundación León XIII, 
organización civil que pretende contribuir al desarrollo integral de comunidades y familias, orientando sus esfuerzos a poblaciones que viven en condiciones de alto grado de marginación y de pobreza. Ese proyecto busca promocionar la cultura del ahorro - voluntario, comunitario, anual, retribuido, con un enfoque de género- entre las personas y hogares más pobres en las localidades rurales en las que trabaja, para que satisfagan necesidades diarias, hacer frente a emergencias y acumular dinero para poder enfrentar gastos, deudas e imprevistos, a fin de mejorar su situación. Esta experiencia no responde, por tanto, a una focalización del problema de la exclusión financiera en el acceso al crédito o la bancarización de los más pobres, tal y como plantean otras iniciativas públicas o privadas - más conocidas y de mayor dimensión-, sino al desarrollo de una cultura del ahorro entre los más excluidos, vinculada a la formación financiera y a procesos de desarrollo e intervención comunitaria más amplios, muy necesarios en un país como México, con altos niveles de rezago en cuanto a inclusión financiera.

La información cualitativa que en este trabajo se ha presentado, procedente de entrevistas personales con actores clave del proyecto de cajas de ahorro, más allá de poner de manifiesto la valoración positiva que de aquel tienen sus beneficiarios finales — $\mathrm{O}$ sus promotores y técnicos—, aporta importantes pistas acerca de las estrategias operacionales y organizativas adoptadas para el buen funcionamiento y desarrollo de dichas estrategias y de sus expectativas de crecimiento.

Los procesos de aproximación a las comunidades, de capacitación de los grupos o de apropiación del proyecto por parte de sus beneficiarios se tornan elementos críticos en el éxito de esas cajas de ahorro. En este sentido importa mucho la confianza que se genere en la población beneficiaria a través de los promotores y la organización promotora, una cuestión esencial en este tipo de iniciativas, a lo que se suma el muy importante trabajo que la Fundación León XIII realiza en la capacitación, supervisión y vigilancia de cada una de sus cajas.

La opción elegida carece de forma jurídica alguna, pero ha logrado extender el proyecto de cajas de ahorro a localidades rurales marginadas de tres estados del sur de México, las cuales se han propuesto como un instrumento clave en las iniciativas de desarrollo económico y social de las localidades en las que la fundación actúa permanentemente bajo un más amplio programa de desarrollo comunitario.

Los datos obtenidos mediante la encuesta entre casi doscientos socios(as) del proyecto de cajas de ahorro aportan una descripción del perfil socioeconómico de sus participantes, confirmándose sus niveles de pobreza y vulnerabilidad. La información ofrecida manifiesta el potencial de ahorro que puede alcanzar la población con altos niveles de marginación y bajos ingresos, condicionado no obstante por características de sus beneficiarios que determinan segmentos 
más —o menos — vulnerables (identificados en la muestra y que corresponde a población de localidades con más altos niveles de marginalidad) y, por ende, con mayores - o menores - capacidades de ahorro.

En cualquier caso, el interés y beneficios de este y otros proyectos de inclusión financiera fuera del sistema formal son elevados, pues así se contribuye a aumentar la cultura financiera y de ahorro entre los más pobres, a mejorar sus vidas, posibilitando nuevos proyectos y mejorando sus ingresos, pero también aumentando la igualdad y la cultura de participación y cooperación dentro de las comunidades, elementos que no siempre son garantizados mediante otros instrumentos o mecanismos de inclusión financiera formal.

\section{Referencias}

Allan, A., Massu, M. \& Svarer, C. (2013). Banking on Change: Breaking Barriers to Financial Inclusion. Plan, Barclays and Care. 32 pp. Recuperado de http://group.barclays.com

Alonso, J., Fernández de Lis, S., Hoyo, C., López-Moctezuma, C. \& Tuesta, D. (2013, junio). La banca móvil en México como mecanismo de inclusión financiera: desarrollos recientes y aproximación al mercado potencial. Documentos de Trabajo, no. 13/19, 57 pp.

Álvarez Castañón, L. C., Páramo Ricoy, T. \& Carpio Mendoza, J. (2011, noviembre-abril). De la inclusión financiera a la intervención social: Una experiencia en el sureste de México. Nova Scientia, 4(7), 125-152.

Banco Mundial (2012). Measuring Financial Inclusion. The Global Findex Database. Policy Research Working Paper 6025. Recuperado de http://data.worldbank.org/data-catalog/financial_inclusion

Centro para la Inclusión Financiera (CIF). (2009). Perspectivas para México de inclusión financiera integral. Informe oficial del Proyecto de Inclusión Financiera en 2020. Accion International. Borrador de discusión, septiembre, 39 pp. Recuperado de www.sagarpa.gob. $\mathrm{mx} /$ agronegocios/boletinpatmir/estudios/Perpectivas\%20Mx\%20Inclusi $\% \mathrm{C} 3 \% \mathrm{~B} 3 \mathrm{n} \% 20$ Financiera\%20ACCION\%20Int.pdf.

Clavellina Miller, J. L. (2012, 17 de mayo). Rezago en la inclusión financiera en México. México: Centro de Estudios de las Finanzas Públicas (CEFP)/LXI Legislatura, Cámara de Diputados, nota informativa 030 .

Comisión Europea (2008). Financial Services Provision and Prevention of Financial Exclusion. Directorate-General for Employment, Social Affairs and Equal Opportunities, Inclusion, Social Policy Aspects of Migration, Streamlining of Social Policies. 
Conde Bonfil, C. (2000a). ONG e instituciones microfinancieras en México. No. 2, 35 pp. Zinacantepec, Estado de México: Programa Interdisciplinario de Estudios del Tercer Sector de El Colegio Mexiquense, A. C.

Conde Bonfil, C. (2000b, marzo). Microfinanciamiento en México. Bibliografia anotada. Materiales de discusión 4. México: Panal de Ideas. La Colmena Milenaria, 128 pp.

Consejo Nacional de Evaluación de la Política de Desarrollo Social (Coneval). (2010). Porcentaje de la población en pobreza según entidad federativa, 2010. Estados Unidos Mexicanos. México: Coneval.

Consejo Nacional de Inclusión Financiera (CNIF). (2013). Reporte de Inclusión Financiera, no. 5, Comisión Nacional Bancaria y de Valores (CNBv), 264 pp. Recuperado de http://www.cnbv .gob.mx/Inclusión

Consejo Nacional de Población (Conapo). (2010). Indice de marginación por identidad federativa y municipio 2010. Recuperado de http://www.conapo.gob.mx/es/CONAPO/Indices_de_ Marginacion_2010_por_entidad_federativa_y_municipio

Demirguc-Kunt, A. \& Klapper, L. (2012). Measuring Financial Inclusion: The Global Findex Database. Policy Research Working Paper, no. 6025, 61 pp. Washington, D.C.: World Bank. Recuperado de www.worldbank.org/globalfindex

Diario Oficial de la Federación (DOF). (2009, 4 de junio). Ley de Ahorro y Crédito Popular. Texto vigente. México. Diario Oficial de la Federación.

Esquivel Martínez, H. (2008). Situación actual del sistema de ahorro y de crédito popular en México. Revista Problemas del Desarrollo, 39(152), 165-191.

Fundación León XIII (2013). Información disponible. México. Recuperado de www.fleonxiii .net/

García Canclini, N. (2001). Culturas híbridas. Estrategias para entrar y salir de la modernidad. México: Paidós.

González-Vega, C. (2012). Profundización financiera rural: políticas públicas, tecnologías de microfinanzas y organizaciones robustas. Revista MBS de Microfinanzas y Banca Social, vol. 1. Almería. Fundación Cajamar, pp. 7-52. Recuperado de www.publicacionescajamar.es

Guinnane, T. (2012). Las primeras cooperativas de crédito alemanas y las actuales organizaciones de microfinanzas. Semejanzas y diferencias. Revista MBS de Microfinanzas y Banca Social, vol. 2. Almería. Fundación Cajamar, pp. 87-109. Recuperado de www.publicacionescajamar.es 
Gutiérrez Reyes, J. P. \& Servan Mori, E. E. (2012, octubre). Análisis descriptivo de los cuestionarios de medios de pago para la titular beneficiaria de Oportunidades y operadores. México: Instituto Nacional de Salud Pública.

Heimann, U. \& Gómez Sainz, S. (2009, octubre). Mapeo de iniciativas de educación financiera en México. Finanzgruppe: Sparkassenstiftung für internationale Kooperation.

Instituto Nacional de Estadística, Geografía e Informática (INEGI) (2013, 25 de abril). Encuesta Nacional de Inclusión Financiera. Boletín de prensa no. 163/13. Aguascalientes, México: Secretaría de Hacienda y Crédito Público/Comisión Nacional Bancaria y de Valores.

Instituto Nacional de Estadística y Geografía (INEGI) (2012, septiembre). Encuesta Nacional de Inclusión Financiera. Análisis descriptivo de los resultados. Aguascalientes, México: Secretaría de Hacienda y Crédito Público/Comisión Nacional Bancaria y de Valores.

Klein, M. (2009). La obra de cooperativas de Friedrich Wilhelm Raiffeisen y sus raíces cristianas. IRU-Courier, (1), 4-16.

La Red de la Gente (2012). Relevancia del cooperativismo en el ahorro y el préstamo. En Una mirada al cooperativismo y su participación en redes para el desarrollo. La Red de la Gente, Servicios financieros y envíos de dinero, Banco de Ahorro Nacional y Servicios Financieros, sNC, 26 pp. Recuperado de www.lareddelagente.com.mx

Leyshon, A. \& Thrift, N. (1995). Geographies of Financial Exclusion: Financial Abandonment in Britain and the United States. Transactions of the Institute of British Geographers, New Series, (20), 312-341.

Martínez Soto, A. P. (2003). Los orígenes del cooperativismo de crédito agrario en España, 18901934. Ciriec-España, (44), 57-104.

Mendizábal Zubeldia, A., Mitxeo Grajirena, J., Olasolo Sogorb, A. \& Zubia Zubiaurre, M. (2008). Reflexiones sobre el origen y las implicaciones de la exclusión financiera. En Castro Silva, E. J. de \& Díaz de Castro, F. J. (Coords.). Universidad, sociedad y mercados globales. Salvador de Bahía: Asociación Española de Dirección y Economía de la Empresa (AEDEM).

Mikkelsen, C. (2014). El mundo indígena 2014. Grupo Internacional de Trabajo Sobre Asuntos Indígenas (IWGIA). Copenhague. Ministerio de Relaciones Exteriores de Dinamarca/ NORAD, 622 pp.

Morfín Maciel, A. (2009). Banca de desarrollo y el apoyo al acceso (México). Santiago de ChileComisión Económica para América Latina y el Caribe (CEPAL), enero, 52 pp. (serie Financiamiento para el Desarrollo). 
Noguer, N. (1912). Las cajas rurales en España y en el extranjero. Teoría, historia y guia práctica, legislación, estatutos y formularios. Madrid. Administración de Razón y Fe.

Peña, X., Hoyo, C. \& Tuesta, D. (2014, junio). Determinantes de la inclusión financiera en México a partir de la ENIF 2012. Documento de Trabajo, no. 14/14, Madrid: BBVA Research.

Programa de Naciones Unidas para el Desarrollo México (pNud México). (2008). Índice de desarrollo humano municipal en México 2000-2005. Base de datos archivo xls. Recuperado de http://www.undp.org.mx/desarrollohumano/competividad/index.html

Raccanello, K. \& Herrera Guzmán, E. (2014, abril-junio). Educación e inclusión financiera. Revista Latinoamericana de Estudios Educativos, 44(2), 119-141.

Reddy, R., Bruhn, M. \& Tan, C. (2013). Capacidades financieras en México. Resultados de la encuesta nacional sobre comportamientos, actitudes y conocimientos financieros. Washington, D.C.: Banco Mundial.

Rojas, J. J. (2012). Cooperativas de ahorro y préstamo en México. De la ausencia al exceso de regulación. Revista MBS, (2), 067-086.

Vázquez, A. (2013). La cuenta de nómina en México: perspectiva de los demandantes y oferentes de servicios financieros. Estudios Económicos CNBv, 2, 135-158.

Zubeldia, A. M., Grajirena, J. M., Sogorb, A. O. \& Zubiaurre, M. Z. (2008). Reflexiones sobre el origen y las implicaciones de la exclusión financiera. International Conference. Asociación Europea de Dirección y Economía de Empresa.

Recibido el 29 de julio de 2014. Aceptado el 16 de junio de 2015. 